\title{
Challenges and Social Experience by People Affected By HIV
}

\author{
Bhuvaneshwari $\mathrm{S}^{1^{*}}$, Gladys Kalpana ${ }^{2}$, Apollo James ${ }^{3}$, \\ SubhaJayanthi.S. $\mathrm{A}^{4}$ \\ ${ }^{1}$ Associate Professor, Department of Pharmaceutical Biotechnology, Nandha College of \\ Pharmacy, Erode, Tamilnadu, Email: s.sribhu@rediffmail.com \\ ${ }^{2}$ Assistant Professor, Department of Pharmacology, Nandha College of Pharmacy, \\ Erode, Tamilnadu, Email: gladyskalpana@nandhapharmacy.org \\ ${ }^{3}$ Associate Professor, Department of Pharmacy Practice, Nandha College of Pharmacy, \\ Erode, Tamilnadu, Email:ajamespharma@gmail.com \\ ${ }^{4}$ Assistant Professor, Department of Mental Health Nursing, Nandha College of \\ Nursing, Erode, Tamilnadu, Email:Subhafreez92@gmail.com \\ ${ }^{*}$ Corresponding Author
}

\begin{abstract}
The point of view of this paper is intended to give a method of coordinating information and abilities. Professionals, for example, social laborers center all the more plainly around the noticed circumstance, featuring the ramifications for activity and assisting with showing up at interventionist choices that relate practically to the difficult circumstance. This paper aims at to tell on how and what are the challenges faced by people affected by HIV and also what are the recommended ways it improve their wellbeing.
\end{abstract}

Keyword: HIV, Challenges, Wellbeing.

\section{Introduction}

Individuals living with HIV/AIDS endure an extraordinary arrangement because of a few elements, for example, constant sickness, disgrace and detachment. The shame joined to HIV/AIDS makes individuals become oppressed by their families, networks, friends, working environments and houses of worship. HIV/AIDS is a deadly illness that can't be restored. There is no distance from the AIDS contamination part. Individuals infected with HIV/AIDS are treated as people living with a lethal, puzzling disease that eventually leads them to pass away, and these insights turn people around living into "the others" of HIV/AIDS, creating in the public eye separation and ridicule. People living with HIV/AIDS are enduring due to stress-related illnesses because they risk unveiling their status in the job insight of the status.

They feature the impediments of divulgence for example that in the event that they unveil, and they will be victimized, vilified or secluded as nobody will need to be related with them. They dread that they will lose their relatives, occupations, companions and sexual accomplices. People living with HIV/AIDS are given their own room in their homes to separate them from others, and they do not share much. The assessment of the scientist is that individuals living with HIV/AIDS need more help as the illness is ongoing and it might make one experience the ill effects of extreme pressure. Absence of help may prompt stressors, for example, gloom, self-destructive reasoning and numerous others. Backing is required from all organizations that are accessible in our general public, beginning from the essential establishment, the family. Individuals who are tainted with HIV face more prominent passionate strain than the vast majority actually do. What is more awful is that the vast majority tainted with the infection face it at a youthful age. Individuals contaminated with HIV are stunned, furious, discouraged, apprehensive, blame ridden or befuddled or experience quite a few these feelings without a moment's delay.

\section{Environmental Perception to Societies Surviving} With HIV/Aids

HIV/AIDS is a terminal illness that affects the entire life of a person, mentally, passionately and socially. Wellbeing, physical and mental issues address pressure for both contaminated and influenced people, for example, relatives and companions. Helps as terminal disease should be tended to with the support of the environment approach. This viewpoint is intended to give a method of coordinating information and abilities. Professionals, for example, social laborers center all the more plainly around the noticed circumstance, featuring the ramifications for 
activity and assisting with showing up at interventionist choices that relate sensibly to the difficult circumstance. This viewpoint stresses that treatment happens in the individual climate setting overall. The environmental point of view expresses that human necessities can't be viewed as separated from the bigger frameworks in which people work. Individuals work in different foundations that are found in the public eye, for example, the family, little gatherings, the local area, the school, the congregation and social offices. The meaning of these structures is established by the hypothesis of social frameworks, which social workers use to explain and interpret these relations. This climate is seen by biologists as settled levels of social association that are intertwined and have mandatory relations across input systems. Social association levels fluctuate with the person as the basic unit of structure in unpredictability. An person adapts to the requests of each new scenario that the individual joins. For psychological specialists or consultants who deal with people dealing with HIV/AIDS, the biological point of view is valuable.

\section{Distresses of Living with HIV/Aids}

HIV/AIDS is a constant ailment that is perceived as distressing, and with tainted persons, this strain starts. For HIV. For people living with HIV/AIDS and people affected by HIV/AIDS, such elements have been recognised as stressors, meaning family and companions. At the point when one is determined to have HIV disease, one is in every case significantly stunned, and this might be trailed by sensations of outrage, dread and hopelessness just as contemplations of self destruction. Contaminated individuals may have numerous feelings of dread. They may fear being trashed, segregated and dismissed. They are questionable of things to come, which means there is vulnerability about who will care for them they should become incapacitated. HIV shame can be hurtful to the individuals who live with the HIV infection from various perspectives. The damage can incorporate a deficiency of confidence just as crumbled social collaborations with others. Extra pessimistic connects of belittling for HIVpositive individuals are despondency, nervousness, forlornness, self-destructive ideation and helpless treatment adherence. There are various negative outcomes related with disgrace, and disgrace itself is normally made out of variables, for example, social dismissal, monetary frailty, disguised disgrace and social disengagement. At the point when the infection advances, it might at last require some type of actual detachment and this is worsened by the going with social disconnection. This is brought about by obliviousness and boundless media-based scaremongering and the way that society has demonstrated little resistance of individuals who are found here and there to have added to their condition through their own ways of life. Rather than culture indicating compassion, fault is very effectively allocated to individuals living with HIV/AIDS. Subsequently, individuals with HIV contamination are hesitant to look for help and they endeavor to save their condition mystery for dread or dismissal and further harm to their mental self-portrait. They lose trust in themselves and endure a deficiency of confidence and self-esteem, occasioned by the dismissal of individuals who are essential to them. Contaminated individuals express blame and remorse for having contracted HIV and furthermore for having potentially tainted others. The sensation of blame might be related with being gay or with sexuality by and large. The confidence of HIV-contaminated individuals is regularly seriously compromised. Being dismissed by companions, partners and friends and family can cause loss of certainty and loss of an individual's feeling of social personality, prompting sensations of diminished self-esteem. HIV-tainted individuals regularly experience the ill effects of discouragement because of numerous misfortunes that they experience in their lives. They have lost numerous things throughout everyday life and reprimand themselves for that. Outrage that is coordinated inwards shows itself as self-fault, reckless conduct or suicide driving forces or aim. The suicide rate among HIV-positive individuals is higher than in everyone. One may pick suicide since one needs to evade agony and distress, decrease the disgrace and sadness of friends and family and attempt to get a proportion of power over one's ailment.

\section{Challenges experienced by individuals with HIV/AIDS}

Most members showed that dread was the stressor encountered by a significant percentage of people dealing with HIV/AIDS. Individuals diagnosed with HIV/AIDS have the least experience with financial difficulties, depression and rejection, and AIDS dementia. Most members showed that the essential support was provided to people living with HIV/AIDS, some showed that people living with HIV/AIDS did not get the fundamental help, and a few were unsure whether or not people living with HIV/AIDS received the critical help. Another kind of assistance that people dealing with HIV/AIDS receive is passionate encouragement. Forswearing of disease by those living with HIV/AIDS was recognised as an effective examination since it is difficult for social professionals to assist the person in achieving the identification stage of the discovery. Forswearing defers the beneficial cycle, as shown by members. The major problems faced by professional cooperatives seem to be believed to be identified with the emotions of people living with HIV/AIDS, denial of their conclusion, criticism, dread of dismissal and destitution. True vulnerability was one of the challenges faced by people dealing with HIV/AIDS demonstrated by the members. Owing to the vulnerability in their muscles, these people also can't function. Family and local rejection, trashing, 
judgment by some, and segregation have been shown to be guilty by certain corrupted citizens, whilst some have not earned the requisite support from family, companions, and local areas. Wii identifies the major challenges faced by people dealing with HIV/AIDS. HIV/AIDS is a questionnaire for people infected with the disease and, moreover, for people infected by the disease, such as family and friends. In comparison, a lack of knowledge about illness is a measure for all tainted and affected people. Refusal of disease for those living with HIV/AIDS has been recognised as an effective test and it is difficult for social workers to help the person arrive at the analytical identification point. The forswearing defers the restorative period, as suggested by participants. Furthermore, it is a test as the parents move away and abandon children as vagrants. Members showed that, in terms of the fact that tainted persons are banned from society, slander was a test. In comparison, taking medications regularly with the duration of their everyday routines is a test for people dealing with HIV/AIDS. There is a lack of guidance on medication once in a while. It appears to be inferred that people living with HIV/AIDS will receive instructive and therapeutic administrations.

\section{Conclusion}

It is suggested that individuals tainted with HIV and influenced by HIV/AIDS get directing, pretesting and post-testing. Stressors, for example, dread, wretchedness, low confidence and self-destructive believing should be tended to during directing meetings by specialist co-ops. Setting up more wellbeing places and utilizing more staff in the medical care framework to offer types of assistance to individuals living with HIV/AIDS ought to be energized. Professionals, for example, social laborers in nongovernmental associations be prepared to deliver compelling and productive social government assistance administrations to individuals living with and influenced by HIV/AIDS. More mindfulness and instruction crusades on HIV/AIDS to dodge vilification of and absence of help to the individuals who live with the infection along with their families. The media could be engaged with these missions. By all way to kill neediness as the discoveries have demonstrated that destitution is one of the difficulties that individuals living with HIV/AIDS go over. This can be accomplished by the making of occupations and preparing of individuals to get independent.

\section{References}

1. Serovich, J.M., Kimberley, J.A., Mosack, K.E. \& Lewis, T.L. 2010. The role of family and friend social support in reducing emotional distress among HIV-positive women. AIDS Care: Psychological and Socio-medical aspects of HIV/AIDS, 13(3):335-341.

2. S. C. Kalichman and L. C. Simbayi, "HIV testing attitudes, AIDS stigmas and voluntary HIV counselling and testing in the Western Cape, South Africa," Sexually Transmitted Infections, vol. 79, pp. 442-447, 2003.

3. S. C. Kalichman and L. C. Simbayi, "HIV testing attitudes, AIDS stigmas and voluntary HIV counselling and testing in the Western Cape, South Africa," Sexually Transmitted Infections, vol. 79, pp. 442-447, 2003.

4. Subedi BK. (2006). Transition of HIV epidemic in Nepal. Kathmandu University Medical Journal, 4 (13), 115 118

5. WHO. (2008a). HIV/AIDS prevention, care and treatment in the South-East Asia Region. WHO: regional office for South-East Asia, pp. 1 - 6.

6. T. P. Eisele, C. Mathews, M. Chopra, L. Brown, E. Silvestre, V. Daries, and C. Kendall, "High levels of risk behavior among people living with HIV initiating and waiting to start antiretroviral therapy in Cape Town South Africa," AIDS and Behavior, vol. 12, no. 4, pp. 570-577, 2008.

7. Germain, C.B. \& Gitterman, A. 1996. The life model of social work practice (2nd ed). New York: Columbia University Press.

8. Bartlett, J.G. \& Finkbeiner, A.K. 2006. The guide to living with HIV infection (6th ed). Baltimore: Johns Hopkins University Press.

9. S. G. Kalichman, D. Rompa, and D. Rompa, "Effectiveness of an intervention to reduce HIV transmission risks in HIV-positive people," American Journal of Preventive Medicine, vol. 21, no. 2, pp. 8492, 2001.

10. C.N.Shankar Rao: Principles of Sociology with an Introduction to Social Thought. 